\title{
IMAGEM DE BRASILEIRO EM LIVROS DIDÁTICOS DE PORTUGUÊS PARA ESTRANGEIROS
}

\author{
Brazilian image in Portuguese textbooks for foreigners
}

Oriana de Nadai FULANETI, UFPB ${ }^{1}$

RESUMO: Com o advento da globalização e de outros fenômenos mundiais, vem crescendo nos últimos trinta anos a quantidade de estrangeiros interessados no Brasil como um destino de residência ou de estabelecimento de parcerias educacionais e profissionais e, concomitantemente, há um aumento no interesse pelo conhecimento da língua portuguesa. Nesse contexto, o presente artigo analisa o livro didático Bem-Vindo! - A língua portuguesa no mundo da comunicação, com o objetivo de verificar a imagem de brasileiro aí presente, trazendo contribuições para a discussão sobre o material didático de PLE produzido em nosso país. Para isso, realizamos a análise do material à luz da teoria semiótica discursiva. Adotando a perspectiva de Benveniste, a semiótica francesa considera que o enunciado é produto de um ato de linguagem no qual um enunciador, levando em consideração seu enunciatário, realiza inúmeras escolhas enunciativas na produção de seu enunciado. A recorrência de determinados traços ao longo dos textos delineia um estilo, um modo de dizer, que confere à totalidade estudada uma identidade e projeta uma imagem (ethos) do sujeito da enunciação (enunciador e enunciatário). Como resultados, tem-se o predomínio da imagem de um cidadão globalizado, que trabalha no mundo corporativo e reside em grandes centros.

PALAVRAS-CHAVE: Livro didático de Português para Estrangeiros; Imagem de Brasileiro; Semiótica Discursiva; Ethos.

ABSTRACT: With the advent of globalization and other global phenomena, there has been over the last thirty years an increase in the amount of foreigners interested in Brazil as their residence or establishment of educational and professional partnerships and a concomitant interest in Portuguese language has raised.In this context, this article analyses the textbook Bem-Vindo! - A língua portuguesa no mundo da comunicação, aiming to verify the Brazilian image in it, bringing contributions to the discussion about the educational material of PFL produced in our country. Therefore, we examined the material based on the discursive semiotic theory. Adopting the perspective of Benveniste, French semiotics considers that the statement is the product of an act of language in which an enunciator, taking into consideration her/his enunciatee, performs countless enunciative choices in the production of her/his statement. The recurrence of certain traits over the text outlines a style, a way of saying, which provides for the whole study an identity and projects an image (ethos) of the subject of enunciation (enunciator and enunciatee). As results, there is the predominance of the image of a globalized citizen, who works in the corporate world and resides in large centres.

\footnotetext{
${ }^{1}$ Professora Adjunta de Língua Portuguesa e Linguística da Universidade Federal da Paraíba. Doutora em Semiótica e Linguísitica Geral (USP). Atualmente é coordenadora do Programa Linguístico-Cultural para Estudantes Internacionais (PLEI/UFPB). od.fulaneti@uol.com.br
} 
KEYWORDS: Portuguese for foreigners' textbooks; Brazilian Image; Discursive Semiotics; Ethos.

\section{INTRODUÇÃO}

Observa-se a partir do final do século XX o crescimento da quantidade de estrangeiros interessados no Brasil como destino de residência ou de estabelecimentos de parcerias educacionais e profissionais. Diversos são os fenômenos que contribuem para isso, entre os quais se mencionam a globalização; a criação do Mercosul (1991); o crescimento econômico vivido pelo país no início do século XXI, que o levou a integrar o Brics (Brasil, Rússia, Índia, China e África do Sul); investimentos na internacionalização da pesquisa, entre outros.

Concomitantemente, houve um acréscimo de interesse pelo conhecimento da língua portuguesa, como revela o progressivo aumento no número de inscritos para a realização do Certificado de Proficiência em Língua Portuguesa para Estrangeiros (CelpeBras), exame desenvolvido e outorgado pelo Ministério da Educação. Enquanto a primeira aplicação, feita em 1998, contou com 127 examinandos, menos de duas décadas depois, em 2016, o Celpe-Bras, em suas duas versões, avaliou mais de dez mil candidatos. (Cf. SHOFFEN; MARTINS, 2016)

De acordo com Almeida Filho (2006) estima-se que o planeta possua mais de três mil línguas vivas atualmente e a língua portuguesa ocupa a sexta posição no ranking de idiomas mais falados. O português está presente em oito países espalhados por quatro continentes. Estes países formaram em 1996 a Comunidade dos Países de Língua Portuguesa - CPLP, um "foro multilateral privilegiado para aprofundamento da amizade mútua e da cooperação entre Angola, Brasil, Cabo Verde, Guiné-Bissau, Moçambique, Portugal, São Tomé e Príncipe e Timor Leste"². O Brasil é o maior país da CPLP e possui um número de falantes nativos do português imensamente superior ao dos demais.

Diante disso, a difusão da variante brasileira da língua portuguesa torna-se essencial tanto para a projeção do Brasil em seus aspectos econômicos, educacionais e culturais, quanto para a expansão da lusofonia. Apesar dessa crescente procura por nossa

\footnotetext{
${ }^{2}$ Descrição da CPLP presente no site da instituição. Disponível em https://www.cplp.org/, acesso em 03/03/2017.
} 
língua, ainda não há no país políticas linguísticas definidas para o Ensino de Português como Língua Estrangeira (EPLE), como afirma Almeida Filho:

\begin{abstract}
Não há nessa década e nem nesta em que vivemos a formulação de uma política oficial deliberada e abrangente para a língua portuguesa seja no âmbito interno do país, seja no âmbito externo, para apoiar a oferta de EPLE que leve em conta: (1) a formação de novos professores em bases contemporâneas, (2) a formação continuada coordenada dos professores nos postos ao redor do mundo, e (3) o estabelecimento de balizas para novos currículos, programas, materiais e exames de proficiência. (ALMEIDA FILHO, 2006, p. 16)
\end{abstract}

Um dos principais meios de preparação para um exame de proficiência e para o aprendizado de línguas estrangeiras é a realização de cursos de idiomas, os quais são ministrados, em grande parte, com o uso de um livro didático. Trata-se de um recurso que cumpre função essencial nas aulas, muitas vezes substituindo determinadas tarefas do professor, como a realização de pesquisas bibliográficas, seleção e análise de textos, escolha das atividades, entre outras.

Nesse contexto, o presente artigo se propõe a analisar o livro Bem-Vindo! A língua portuguesa no mundo da comunicação, sob a perspectiva da semiótica discursiva. Acredita-se que a construção de políticas oficiais para o EPLE exige um estudo do "estado da arte" de nossa produção - teses, dissertações, artigos e material didático e, portanto, estudar um livro didático que tem sido reeditado com frequência desde o seu surgimento ${ }^{3}$, visa a trazer contribuições para a reflexão sobre o ensino de PLE que temos e o ensino que queremos.

Entre as perguntas motivadoras da análise, duas predominam: qual a imagem de brasileiro presente no livro? E de Brasil? Considerando a relação entre língua e cultura, faz-se importante investigar o que é dito, o que é enfatizado, e o que é silenciado no livro, escolhas que se realizam em função da visão que se quer transmitir do país e de sua gente, mas também da imagem que se tem do outro e da projeção que se faz da visão que esse outro tem de nós.

A perspectiva discursiva aborda a língua em uso, considerando elementos sociais, históricos e culturais na construção do sentido. Adotando a proposta de Benveniste, a semiótica francesa considera que o enunciado é produto de um ato de linguagem no qual um enunciador, levando em consideração seu enunciatário, realiza inúmeras escolhas enunciativas na produção de seu enunciado, tais como valores; tipo de narratividade; projeções das categorias de pessoa, tempo e espaço; seleção dos temas e a forma de

\footnotetext{
${ }^{3}$ Lançado em 1999, o livro alcança a nona edição em 2009.
} 
explorá-los; vocabulário, entre outros. A recorrência desses traços, ou de alguns deles, ao longo dos textos delineia um estilo, um modo de dizer, que confere à totalidade estudada uma identidade e projeta uma imagem (ethos) do sujeito da enunciação (enunciador e enunciatário). A proposta consiste, portanto, em recolher os traços linguísticos disseminados ao longo do livro, verificando qual é, ou quais são as imagens de Brasil e de brasileiro aí presentes e predominantes.

Para isso, apresentam-se inicialmente alguns conceitos-chave da semiótica francesa que servem como base para a pesquisa. Em seguida, na realização das análises, busca-se depreender, a partir da leitura dos textos e diálogos presentes no livro, os principais temas associados aos brasileiros e a forma como são figurativizados, com a escolha do vocabulário e a disseminação de valores. Por fỉm, são discutidas algumas considerações sobre os resultados obtidos e sua importância para as reflexões no quadro do ensino de PLE.

\section{SEMIÓTICA E ETHOS}

A semiótica surge no final dos anos 1960 com a proposta de ser uma teoria geral do texto e da significação. No intuito de depreender a produção de sentido de um texto, Greimas (1975; 1983; s.d.) desenvolveu uma metodologia que considera a articulação entre um plano do conteúdo e um plano da expressão e categorias gerais que pudesse contemplar a totalidade dos textos, manifestados em qualquer materialidade e definir as estratégias enunciativas particulares dos textos concretos.

A produção do sentido de um texto é concebida pela teoria greimasiana como um percurso gerativo constituído de três patamares: o fundamental, o narrativo e o discursivo. No fundamental, uma oposição abrangente e abstrata organiza o mínimo de sentido a partir do qual o texto se articula. No nível narrativo têm-se as transformações advindas da busca dos sujeitos por valores investidos em objetos. Uma transformação narrativa mínima consiste na mudança de estado de um sujeito, podendo esta resultar em conjunção ou disjunção. Assim, quando um aluno compra um livro, realiza-se uma operação conjuntiva, ou seja, ele passa do estado de não possuir para o estado de possuir o livro. Opostamente, caso o aluno perca o livro, ocorrerá uma disjunção. Sujeito e objeto, no caso o aluno e o livro, são funções actanciais, podendo, tanto a função de sujeito quanto a de objeto, ser preenchidas por um animal, uma nação, um bem material etc. Os objetos 
são revestidos de valores, os quais não são fixos. Aprender um idioma significa entrar em conjunção com um saber que pode representar algo útil e necessário para uns e mero status para outros.

No nível discursivo, as estruturas narrativas são convertidas em discurso por um sujeito da enunciação, por meio da projeção das categorias sintáticas de pessoa, tempo e espaço e da disseminação de temas e figuras que constituem a cobertura semântica do discurso.

Por conta de sua herança benvenistiana, a semiótica discursiva sustenta que todo enunciado é produto de um ato de linguagem e necessariamente pressupõe uma instância enunciante identificável por meio de marcas deixadas no enunciado. Como em todo ato de linguagem, essa instância enunciante pressuposta (enunciador) se estabelece em uma interlocução com um enunciatário - o perfil de um "para quem" o enunciado foi concebido - igualmente pressuposto ao ato de linguagem em si (enunciado). O perfil do sujeito da enunciação, portanto, compreende um enunciador e um enunciatário e sua identidade se dá a partir das marcas deixadas no enunciado (FIORIN, 1996).

Além da projeção das categorias de pessoa, tempo e espaço, o enunciador também escolhe os temas abordados e as figuras que revestem esses temas. Os textos classificamse como predominantemente temáticos ou figurativos. Os temas concretizam os investimentos abstratos nos valores do nível narrativo, sua natureza é conceitual. Assim, os discursos temáticos classificam, explicam e organizam o mundo. Um percurso temático "é uma distribuição sintagmática de investimentos temáticos parciais" (GREIMAS; COURTÈS, s.d., p. 453) que permite a discursivização da narrativa de maneira coerente. As figuras correspondem aos elementos que remetem ao mundo natural. As figuras também se ordenam sintagmaticamente para compor os percursos figurativos, podendo revestir um ou mais percursos temáticos.

Arrisquemos um exemplo para não ficarmos na instância da pura abstração. Consideremos um programa narrativo que trate da conjunção de um sujeito com o valor saber. Este valor pode ser tematizado pelo saber escolar e figurativizado por um percurso que contenha as figuras: classe, carteira, lousa, mesa, livros, lápis, caneta, diploma etc. Essa operação é resultado de uma escolha enunciativa feita a partir de um estoque de temas e figuras que varia de acordo com a cultura, o momento histórico, a condição social etc. É importante destacar que desse estoque fazem parte também símbolos, estereótipos e outras manifestações discursivas do senso comum (temas e cenários consagrados, expressões fixas etc.), que são normalmente associadas a narrativas de cognição, ação ou 
paixão. Dessa forma, assim como, em nossa sociedade, caneta e caderno geralmente fazem referência ao estudo, coração e flecha remetem ao amor.

É no nível discursivo que a ideologia se manifesta de forma mais explícita. O sujeito da enunciação, na produção de seu enunciado, é responsável pela axiologização dos conteúdos semânticos do discurso e pela orientação da visão de mundo, isto é, pela ideologia adotada. Desse modo, como aponta Barros, a enunciação "assume [...] uma dupla tarefa de mediação, entre as estruturas narrativas e sêmio-narrativas e entre o discurso e o contexto sócio-histórico" (1988, p.143).

A reunião do enunciador e do enunciatário, ambos responsáveis pela produção do discurso, constitui o sujeito da enunciação. Este sujeito é concretizado por temas e por figuras, formando o ator da enunciação, cuja imagem constitui o ethos ${ }^{4}$. Tal imagem não se depreende a partir de um único enunciado, que remete à imagem do narrador, mas de um conjunto de textos. Torna-se, dessa forma, bastante relevante o recorte de uma totalidade. $\mathrm{Na}$ presente pesquisa, a totalidade compõe-se pelo conjunto de textos presentes no livro didático estudado.

Mas, como é possível depreender o ethos? Fiorin, buscando responder a essa questão, traz a seguinte resposta:

\begin{abstract}
Onde se encontram, na materialidade discursiva da totalidade, as marcas do éthos do enunciador? Dentro dessa totalidade, procuram-se recorrências em qualquer elemento composicional do discurso ou texto: na escolha do assunto, na construção das personagens, nos gêneros escolhidos, no nível de linguagem usado, no ritmo, na figurativização, na escolha dos temas, nas isotopias, etc. (FIORIN, 2004, p. 125)
\end{abstract}

Ao observarmos as escolhas do sujeito da enunciação na construção de seu enunciado, sejam elas no nível fundamental, narrativo ou discursivo, encontramos recorrências que vão delinear o ethos.

Interessa para a nossa análise também a noção de ethos prévio, mais explorada pela Teoria da Argumentação e pela Sociologia. Para seus adeptos, a imagem do orador devese mais à função e ao papel que este exerce do que ao discurso proferido. O éthos prévio reside, dessa forma, na imagem do sujeito no mundo, exterior ao discurso. Segundo a

\footnotetext{
${ }^{4} \mathrm{O}$ conceito de éthos surge com os retores da Antiguidade e se encontrando explicado no primeiro livro d'A Retórica de Aristóteles. Para o Estagirita, o ethos reside no caráter moral do orador, na imagem que este constrói no discurso para inspirar confiança no auditório e tornar sua persuasão mais eficaz. A partir da década de 1970 este conceito é retomado e reinterpretado por diversas teorias do discurso e da sociologia, como a Teoria da Argumentação, Análise do Discurso, Semiótica Discursiva e Sociologia dos Campos.
} 
estudiosa de argumentação, Ruth Amossy, e nesse ponto concordamos com a autora, não se pode dissociar completamente as imagens externa e interna do enunciador, pois o éthos prévio do orador "faz parte da bagagem dóxica dos interlocutores e é necessariamente mobilizado pelo enunciado em situação" (AMOSSY, 2005, p. 136-137). Na mesma direção, o analista de discurso Dominique Maingueneau (2005) afirma que o enunciador, em seu fazer enunciativo, considera sua imagem pré-existente (éthos pré-discursivo) e, de acordo com o objetivo, constrói seu discurso para reforçá-la, transformá-la, neutralizá-la etc. Para a Semiótica, o éthos prévio corresponde à imagem do sujeito formada a partir de discursos anteriormente proferidos por ele e sobre ele. Nesse sentido, a produção do livro didático leva em consideração as imagens prévias do seu autor e de seu leitor, escolhendo reforçá-las, adaptá-las, transformá-las etc., estratégias que são depreensíveis por meio da análise do enunciado e das marcas de enunciação nele deixadas.

\section{BEM-VINDO！ ALGUMAS CONSIDERAÇÕES SOBRE O LIVRO}

Para fazer a apresentação do livro estudado e justificar a relevância do corpus escolhido, reproduzimos abaixo a descrição da obra feita pela editora:

\footnotetext{
Campeão de vendas e referência quando se fala em ensino de Português como Língua Estrangeira, Bem-Vindo! A Língua Portuguesa no mundo da Comunicação é um curso completo voltado a jovens e adultos de todos os níveis, do básico ao avançado. Amplamente adotado em escolas de idiomas, universidades e aulas corporativas no mundo todo, Bem-Vindo! já chegou a impressionantes 140 mil exemplares vendidos, somente do Livro do Aluno. Dividido em cinco grupos ("Eu e você", "O Brasil e sua língua", "A sociedade e sua organização", "O trabalho e suas características" e "Diversão - Cultura") ensina, por meio de textos variados e exemplos práticos, as diferentes nuances da língua portuguesa. (Disponível em http://www.sbs.com.br/sp, acesso em 20/02/2017).
}

Nesta pesquisa estamos trabalhando com a terceira reimpressão da sétima edição, de 2008. Como afirmado acima, o livro divide-se em cinco grupos de quatro unidades cada, as quais apresentam progressivamente conteúdos da língua portuguesa. Encontramse presentes em todas as unidades seções com ênfase em gramática, vocabulário, além de atividades de leitura e produção de texto e de conversação. Algumas unidades também contêm textos que tratam especificamente da história e da cultura brasileiras.

\section{Brasil e brasileiros mostrados}


As imagens que seguem servem de base ilustrativa para a análise. Ressalte-se, porém, que o livro está sendo considerado em sua totalidade.
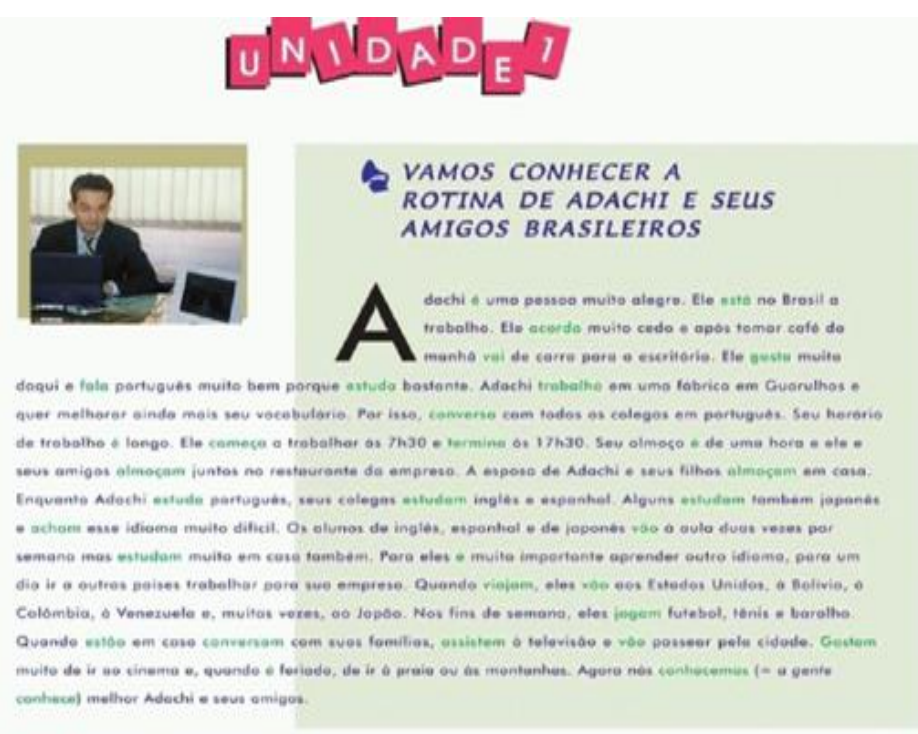

Copie no seu caderno os verbos que aparecem no texto e coloque-os $n$ Exemptoi

E vocez o que voce gosta de fazer nas horas livrest

ingles? espanhol, japonés ou ingles?

W Observe as seguintes estruturas, treine-as e depois pratique falando sobre a , rotina de um amigo seu.
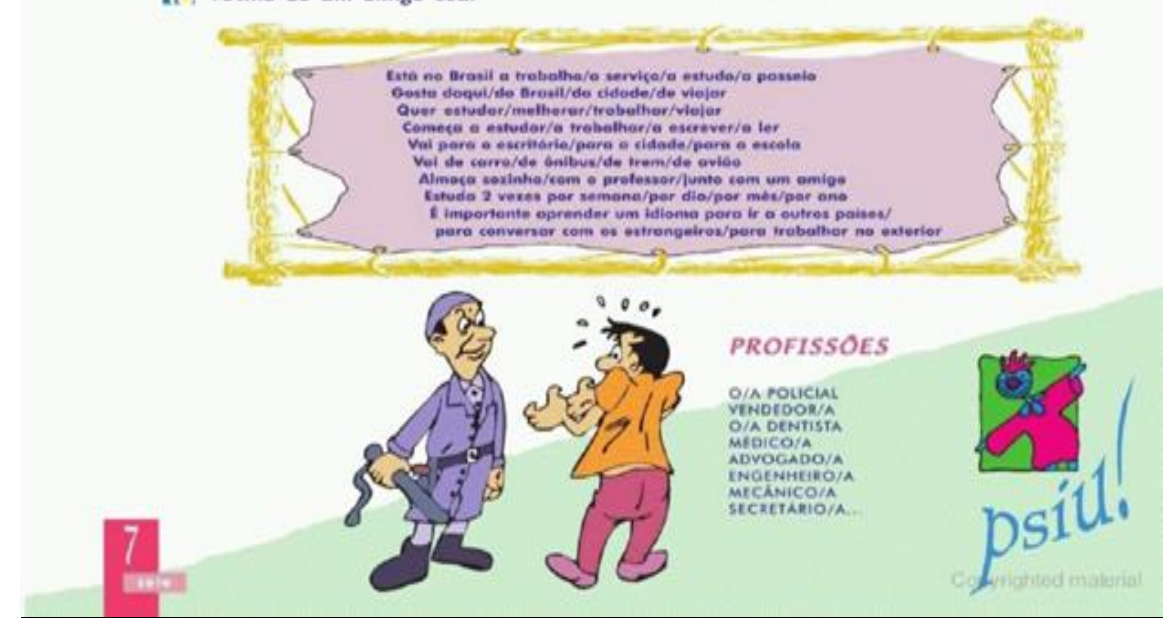

Figura 1. A rotina de Adachi. Fonte: FLORISSI, PONCE E BURIM, 2008, p. 7. 


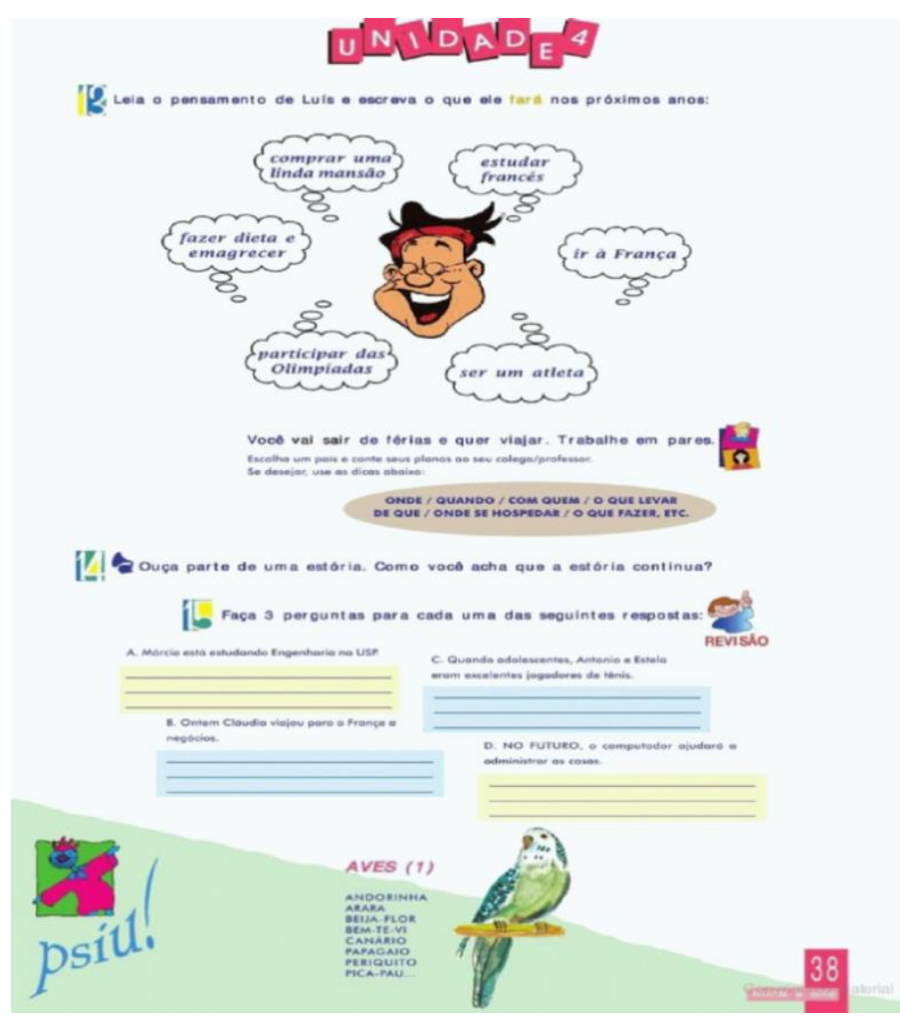

Figura 2. O futuro de Luís. Fonte: FLORISSI, PONCE E BURIM, 2008, p.38.

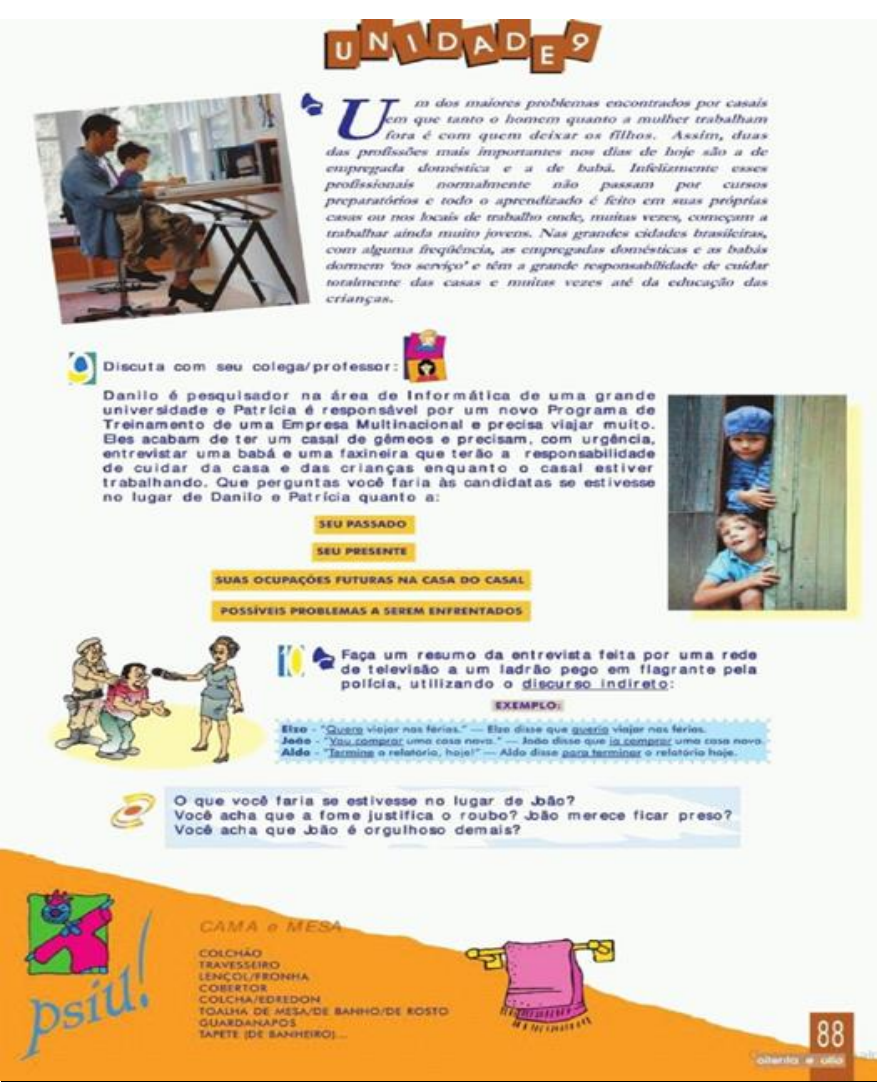

Figura 3. O problema de Danilo e Patrícia. Fonte: FLORISSI, PONCE E BURIM, 2008, p.88. 


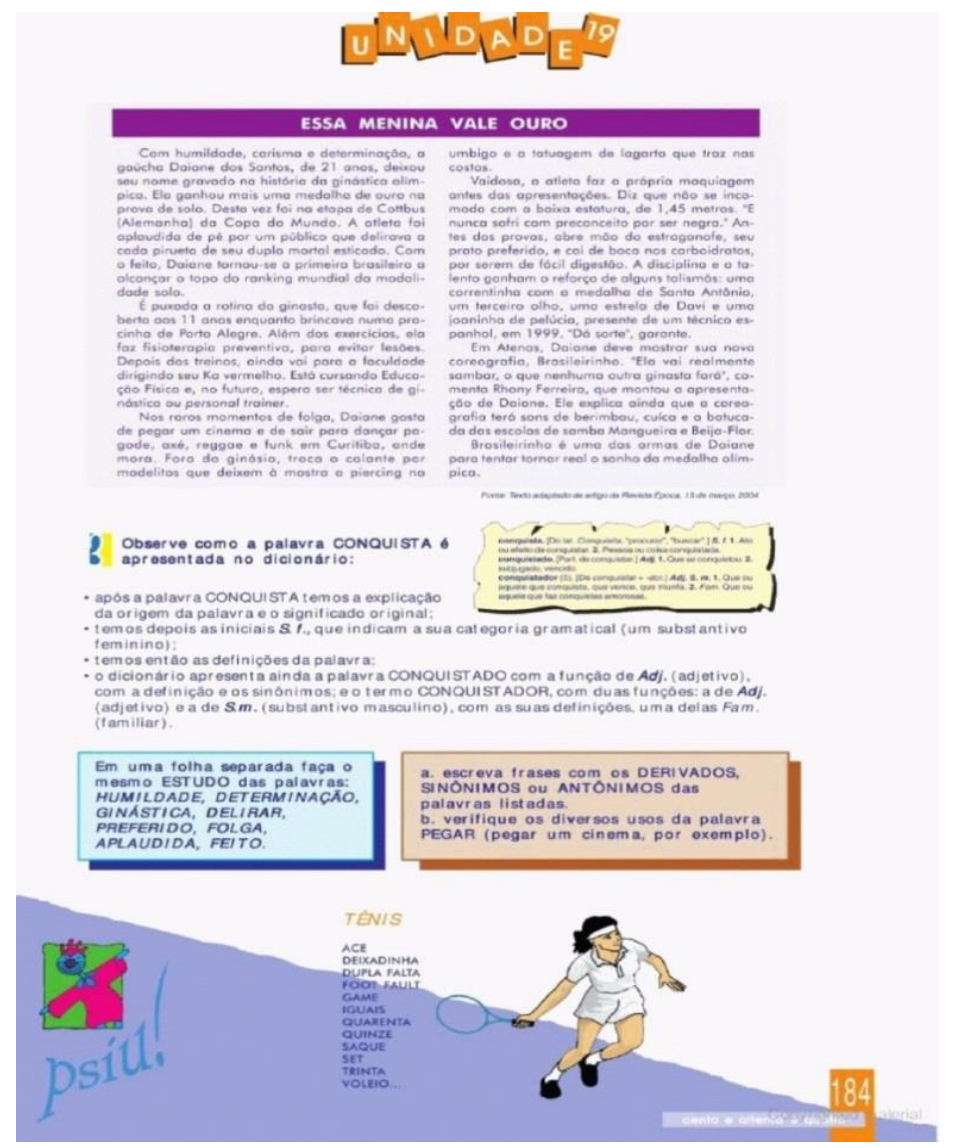

Figura 4. A vida de Dayane dos Santos. Fonte: FLORISSI, PONCE E BURIM, 2008, p. 184.

As principais formas de narratividade presentes no livro são transformações conjuntivas nas quais se projetam um sujeito em vias de conquistar algo. Os objetos de valor a serem alcançados com essa conquista relacionam-se a trabalho, viagem, conhecimento, dinheiro e bem-estar, sempre apresentados em perspectiva de melhora: ganhar mais, falar mais línguas, viajar mais, possuir mais bens materiais etc. Porém, não se trata de uma conjunção brusca, mas de um processo resultante de muito empenho. Seja no revestimento semântico do seu Adachi, empresário japonês, do casal Danilo e Patrícia, cuja nacionalidade não se especifica (provavelmente brasileiros) ou da atleta brasileira Daiane dos Santos, ao longo de grande parte das páginas o que se valoriza é o sujeito esforçado.

O trabalho corresponde a um percurso temático central no livro. Desse modo, mesmo havendo um grupo de quatro unidades voltado para o assunto, no qual se encontram as mais variadas discussões em torno do tema, como cultura e competitividade (p. 143), responsabilidade social da empresa (p. 135), adaptação das empresas ao mercado de trabalho globalizado (p. 141), ecologia na empresa (p. 148), home office (p. 128), 
ginástica na empresa para evitar lesões (p. 167) etc, verificam-se também em outros grupos a ampla presença do mundo do trabalho: apresentação de um gerente; descrição da rotina de um homem que trabalha em uma empresa; viagem a trabalho, entre outros.

Observa-se, tanto pelas fotos quanto pelos textos, o predomínio de adultos, principalmente homens. Surgem poucos jovens ou crianças. Esse adulto é apresentado como um trabalhador do mundo globalizado - são estrangeiros que moram no Brasil ou brasileiros que estão a trabalho no exterior, representantes, na maioria das vezes, de profissões valorizadas positiva e financeiramente na sociedade: advogados, engenheiros, médicos e sobretudo gerentes e diretores de empresas multinacionais.

Um segundo tema recorrente ao longo das páginas refere-se ao estudo e à aprendizagem, com ênfase para as línguas estrangeiras. Assim, projeta-se no enunciado a situação vivida na enunciação, uma vez que se trata de um livro didático de língua portuguesa para estrangeiros. Outro tema bastante presente são as viagens. No Brasil, surgem diversos destinos, como Rio de Janeiro, Amazônia, Foz do Iguaçu, Pantanal, Brasília e as "belas praias do nordeste". Há também destinos internacionais, como se pode observar no texto abaixo:

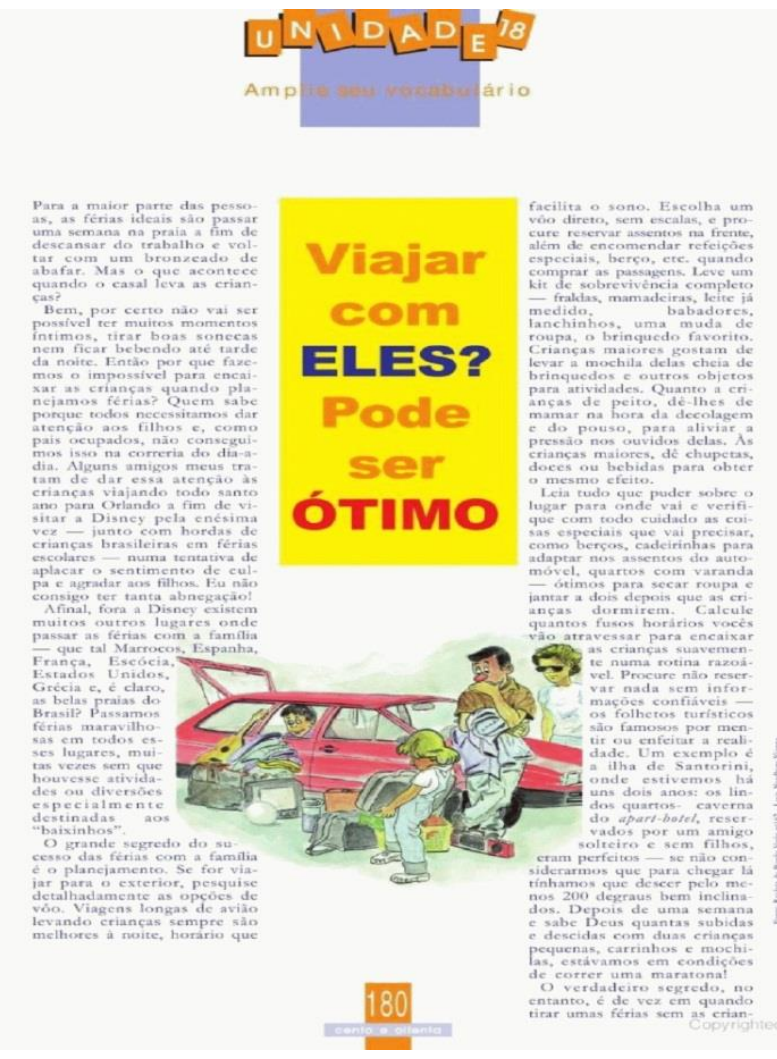

Figura 5. Férias com as crianças. Fonte: FLORISSI, PONCE E BURIM, 2008, p. 180. 
O texto anterior mostra um pai de família que tem como opções de férias viajar para a Disney, Marrocos, Espanha, França, Escócia, Estados Unido, entre outros. O assunto principal é como passar boas férias com os filhos, mas as possibilidades cogitadas mostram uma "boa" condição financeira da família representada. A presença do sujeito economicamente bem-sucedido verifica-se ao longo de diversas unidades, como no diálogo "Alugando uma casa" (p. 81), quando o cliente explica o tipo de casa que procura: "tem que ter no mínimo três dormitórios, um deles suíte"; ou quando um grupo chega ao restaurante e é recebido pelo garçom: "Quantas pessoas? Fumantes ou não fumantes? Estejam à vontade" (p. 71). Os espaços representados são boas moradias, boas escolas, bons restaurantes, teatros etc.

Ainda com relação ao espaço, chama a atenção o predomínio de situações referentes à realidade de grandes cidades da região sudeste, sobretudo São Paulo, imensamente mais mencionada do que as demais localidades. Tal concentração espacial também foi observada por Barbosa:

Há que se ressaltar uma centralização dos episódios ligados a grandes centros, sobretudo ao eixo Rio-São Paulo, o que no nosso entendimento, prejudica a imagem (ausente) de outras importantes cidades e regiões brasileiras (2015, p. 234)

Esse cidadão bem sucedido, globalizado e habitante dos grandes centros pertence normalmente ao mundo dos negócios, dos investimentos. Para ele, estudar idiomas é uma consequência da vida que leva. Corroboram a construção dessa imagem as diversas reportagens ou adaptações de reportagens extraídas do jornal Gazeta Mercantil.

Nesse sentido, na oitava unidade, intitulada "O país e seu idioma", dedicada ao Brasil e à língua portuguesa, os textos e ou atividades surgem com os seguintes títulos: "Projeto USP no Timor", sobre brasileiros que estão ensinando português no Timor Leste; "Português do Brasil - Português de Portugal", apresentando a diferença das duas variantes da língua portuguesa; “O que você sabe sobre o Mercosul?????”, trazendo informações a respeito das relações comerciais na América do Sul; "Fortaleza tem a primeira casa High Tech" e "Técnica italiana para combater pássaros", sobre tecnologias avançadas utilizadas no Brasil; "Do Brasil para o mundo, agora até com certificado de rabino", sobre a produção brasileira de cachaça. Na mesma perspectiva, podemos ler os textos "Cresce participação estrangeira em negócios de caju. Indústrias alugam equipamentos para grupos internacionais beneficiarem o principal produto de exportação do Ceará" (13 $13^{\mathrm{a}}$ unidade, p. 125) e "Bahia, as razões do sucesso. O Estado é hoje um 
exemplo de quanto vale a pena investir em infra-estrutura turística" (17 unidade, p. 170). Trata-se de um Brasil empreendedor, globalizado, que expõe seus produtos para exportação e suas especificidades linguísticas, mostrando ter potencial, força e identidade.

A construção em espelho de um cidadão globalizado, investidor bem sucedido, trabalhador que estuda línguas, viaja, pratica esportes, podendo ser tanto brasileiro quanto estrangeiro, corresponde à imagem predominante de sujeito presente na obra. Esse sujeito, por sua vez, constrói o Brasil que predomina na obra. Juntos, Daiane, o empresário japonês, a gerente uruguaia, o produtor de cachaça, o sócio da castanha, constituem o país.

A imagem mencionada surge mostrada, mas não dita. Não há, nesse caso, presença de estereótipos. A lição sobre esportes, por exemplo, não enfatiza o futebol. Não são textos produzidos com o propósito de "falar de si", mas textos que, discorrendo sobre outros temas, desvelam e revelam um modo de ser e de agir no mundo.

\section{Brasil e brasileiros ditos}

Por outro lado, o livro também traz o Brasil que fala da sua História, da formação do seu povo, da sua música, literatura e do seu folclore.

Há quatro textos sobre a História do Brasil, cada um com um pouco menos de uma página. São eles:

1) Do descobrimento à Independência (p.90), que aborda de 1500 a 1822;

2) Do Império à República (p. 100), que trata da proclamação da independência à década de 1980;

3) O Brasil Contemporâneo (p. 110) abrange apenas a década de 1980;

4) Brasil: Estabilidade Econômica x Estabilidade Social, sobre a década de 1990.

Todos os textos foram extraídos do Almanaque Abril e contém informações essencialmente de regimes políticos e ciclos econômicos, em ordem cronológica.

Além da série sobre História, há "Gente e cultura brasileira", composta também de quatro textos: Quem somos, afinal? (1) (p. 162); Quem somos, afinal? (2) (p. 172), que discorrem sobre os seguintes "personagens típicos" entre o povo brasileiro: gaúcho, caboclo, caipira, sertanejo, mulato, pantaneiro, seringueiro, caiçara, jangadeiro e mestiço oriental. O terceiro texto, "Literatura Brasileira" (p. 182), aborda a literatura brasileira do 
século XVII ao XXI, enfatizando o que o que é chamado de regionalismo, e deixando de fora nomes como Machado de Assis, Clarice Lispector ou Guimarães Rosa. O quarto texto, "Música Popular", aborda a música brasileira do século XVIII ao XXI. Assim como as informações sobre História, aquelas a respeito de literatura e música também são retiradas do Almanaque Abril.

Seguindo o mesmo estilo, a última página da vigésima unidade traz um texto também retirado do Almanaque Abril, "Carnaval", o qual se inicia com o surgimento do carnaval no mundo e prossegue tratando das mais variadas formas de manifestação do fenômeno no Brasil, de sua chegada, no século XVII, aos dias atuais. A última unidade contém ainda listas de personagens do folclore brasileiro e de festivais de arte existentes no país. Ressalte-se que os textos sobre o Brasil estão concentrados no final do livro.

Procurando informações sobre o extinto Almanaque Abril, pode-se ler que se trata de uma enciclopédia, termo cuja definição aponta as seguintes acepções no dicionário Houaiss ${ }^{5}$ :

1. conjunto de todos os conhecimentos humanos

2. obra que reúne todos os conhecimentos humanos ou apenas um domínio deles e os expõe de maneira ordenada, metódica, seguindo um critério de apresentação alfabético ou temático.

O conjunto de conhecimentos exposto na enciclopédia procura contemplar toda a gama de elementos existentes. Busca-se, em um curto espaço físico, trazer o máximo de informações possível sobre a diversidade da nossa cultura e da nossa construção identitária. Por outro lado, a concentração de muitas informações dificulta a apreensão das mesmas. Essa forma de textualização traz um efeito de sentido de objetividade, de cientificidade e distanciamento. Os elementos apresentados surgem isolados, como informações científicas, curiosidades históricas e não como eixo central de nosso cotidiano nacional. No Almanaque, assim como no dicionário, as informações surgem estáticas, não em uso.

\section{CONSIDERAÇÕES FINAIS}

\footnotetext{
${ }^{5}$ Disponível em https://educacao.uol.com.br/dicionarios , acesso em 02/03/2017.
} 
A expansão de uma língua é resultado de uma série de fatores e reflete em diversos âmbitos da sociedade, como educação, cultura, economia, entre outros. Uma vez que o ensino de línguas para estrangeiros corresponde a uma das formas de difusão das línguas, a produção de material didático torna-se parte da política de internacionalização do país.

A análise de Bem vindo! A língua portuguesa no mundo da comunicação sob a perspectiva da semiótica discursiva, ao sistematizar as constâncias que surgem nas profissões, formas de lazer, descrições do cotidiano, nos espaços mais frequentados e nas temáticas mais discutidas, revela o predomínio da imagem de um cidadão globalizado, habitante de grandes centros, que trabalha muito, viaja bastante, estuda línguas, pratica esportes, cuida da saúde e desfruta de um certo "conforto" material. Trata-se de um sujeito cuja imagem se constrói mais fortemente voltada para o outro do que para si, para o público-alvo estratégico. O ethos prévio do enunciatário, a imagem que o enunciador tem do estrangeiro que chega ao Brasil ou que utiliza o material, compõe os traços mais fortes desse sujeito.

De modo complementar, a investigação mostra que as seções votadas para a História do Brasil, formação do povo brasileiro, música, literatura e folclore surgem, em sua grande maioria no final do livro, concentram grande quantidade de informações, as quais são apresentadas com efeito de sentido de objetividade e distanciamento, o que reforça a adesão a uma axiologia mais voltada para os "negócios" do que para a diversidade cultural. Poderíamos pensar, com tudo isso, que há uma forte coerção dos fatores econômicos sobre o ensino de português como língua estrangeira. Aliás, onde mesmo esta coerção não está presente?

\section{REFERÊNCIAS}

ARISTÓTELES. Retórica. Lisboa: Imprensa Nacional - Casa da moeda, 1998.

ALMEIDA FILHO, J. C.P. O Ensino de Português como Língua Não- Materna: Concepções e Contextos de Ensino. In: Biblioteca Virtual do Museu da Língua Portuguesa. São Paulo, 2006. Disponível em: http://www.estacaodaluz.org.br.

AMOSSY, R. O ethos na intersecção das disciplinas : retórica, pragmática, sociologia dos campos. In : AMOSSY, Ruth (Org.). Imagens de si no discurso. A construção do ethos. São Paulo: Contexto, 2005, p.119-144.

BARBOSA, L.M.A. Procedimentos Interculturais e Diversidade Étnico-Racial do Brasil em dois Livros Didáticos de Português para Estrangeiros. Entre-Línguas. Araraquara, v.1, n.2, pp. 223-236, 2015 
BARROS, D. L.P. Teoria do discurso: fundamentos semióticos. 2.ed. São Paulo: Humanitas, 1988.

FIORIN, J. L. As astúcias da enunciação. São Paulo: Ática, 1996.

O ethos do enunciador. In: CORTINA, A. e MARCHEZAN, R.C. (orgs.). Razões e sensibilidade. Araraquara, v.1, 2004, p. 117-138.

FLORISSI, S.; PONCE, M. H. O.; BURIM, S. R. B. A. Bem-vindo! A língua portuguesa no mundo da comunicação: Português para estrangeiros. São Paulo: SBS, 2008.

GREIMAS, A.J. Sobre o sentido: ensaios semióticos. Petrópolis: Vozes, 1975. Du Sens II. Paris: Seuil, 1983. 